\title{
Privatization in the presence of foreign competition and strategic trade policies
}

\author{
Bouwe R. Dijkstra ${ }^{a}$, Anuj Joshua Mathew $^{* b}$ and Arijit Mukherjee ${ }^{c}$ \\ ${ }^{a}$ School of Economics and GEP, University of Nottingham, UK, CESifo, Germany \\ ${ }^{b}$ Analytical Services Directorate, Ministry of Justice, United Kingdom \\ ${ }^{c}$ Loughborough University and CFGE, UK, CESifo, Germany and RCIE, City Univer- \\ sity of Hong Kong, Hong Kong
}

March 2014

\begin{abstract}
:
Recent evidence shows that developing and transition economies are increasingly privatizing their public firms and also experiencing rapid growth of inward foreign direct investment (FDI). In an international mixed oligopoly with strategic tax/subsidy policies, we analyze the interaction between privatization and FDI. We find that the incentive for FDI increases with privatization. However, the possibility of FDI reduces the degree of privatization. Our paper shows that FDI policies reducing the fixed-cost of undertaking FDI may need to complement the privatization policies to attract FDI and to improve domestic welfare.
\end{abstract}

JEL Classification: F12, F18, F21, L33.

Keywords: Privatization, Product tax/subsidy, Foreign Direct Investment, Trade, Privatization.

\section{Introduction}

Over past two decades, one of the most significant market reforms in the developing and transition economies that has helped to attract large foreign direct investment

\footnotetext{
${ }^{*}$ Corresponding author: Ministry of Justice, 102 Petty France, London, SW1H 9AJ, UK. Tel. +44 203 3343834; email Anuj.Mathew@justice.gsi.gov.uk

The author would like to acknowledge the support through a Research Project Funding (Ref: ECO2010-18680) from Ministerio de Ciencia E Innovacion, (Ministry of Science \& Innovation), Spain. The authors are solely responsible for the views presented here but not their organizations. The usual disclaimer applies.
} 
(FDI) inflows is privatization of their state-owned enterprises (UNCTAD, 2002). While empirical evidence suggests a negative correlation, ${ }^{1}$ the literature has only just begun to address the causality between state ownership and foreign capital. ${ }^{2}$

Nationalization of firms acts as a disciplining device in an imperfectly competitive market by increasing output of the state-owned firms. However, as shown in Mukherjee and Suetrong (2009), the possibility of FDI affects the incentive for nationalization significantly. They show that there can be a two-way relation between FDI and privatization: the incentive for privatization increases the incentive for FDI and the possibility of FDI increase the foreign firm's incentive for FDI. While Mukherjee and Suetrong (2009) show that FDI and privatization can be complementary, they have ignored an important aspect, viz., the use of tax/subsidy policies, which can be used to eliminate (or at least to reduce) inefficiency due to imperfect competition in the product market. We take up this issue in this paper and use an international oligopoly model to show the relation between state ownership and FDI in the presence of strategic tax/subsidy policies. ${ }^{3}$

We consider an open-economy mixed oligopoly model where a domestic nationalized firm and a foreign private firm compete in the domestic market with homogeneous products, which are subject to tax/subsidy imposed by both countries. The foreign firm decides whether to serve the domestic market either through export or through FDI and the domestic government determines the optimal degree of private ownership in the nationalized firm. In line with the privatization literature, discussed in the following Section 2, and following the practice of many countries, we consider privatization as transfer of public firm's ownership from the government to the investors of the domestic country. ${ }^{4}$

\footnotetext{
${ }^{1}$ Baer (1994) shows that, as the state ownership in Latin America reduces, the presence of foreign capital increases. Using annual data of eight Asian and nine Latin American and Caribbean countries for 1990-99, Gani (2005) shows that privatization is positively correlated to FDI. Focusing on the Central and Eastern European countries (CEECs), Marlevede and Schoors (2005) have shown that privatization history positively affects FDI.

${ }^{2}$ In a Cournot oligopoly setting, Mukherjee and Suetrong (2009) show that privatization and FDI are mutually reinforcing.

${ }^{3}$ Production tax could be in the form of stumpage or natural resources consumption tax - a tax to help ensure the long run sustainability by making people be more aware of natural resource consumption.

${ }^{4}$ Before 1996, the auction of shares of the Indian public sector enterprises was restricted to dispersed
} 
In this framework, we show that privatization generally increases the foreign firm's incentive for FDI. However, when looking at the effects of export and FDI on privatization, we find that complete privatization is optimal under export by the foreign firm but partial privatization is optimal if the foreign firm undertakes FDI. Hence, the threat of FDI reduces the optimal degree of privatization in the presence of taxation. Whether or not FDI occurs in equilibrium, we find that partial privatization is the equilibrium strategy. Our paper shows that FDI policies reducing the fixed-cost of undertaking FDI may need to complement the privatization policies to attract FDI and to improve domestic welfare.

The rest of the paper is organized as follows. We review the relevant literature in Section 2. Section 3 describes the model. Section 4 shows the market outcomes under export and FDI. Section 5 derives the condition for a profitable FDI by the foreign firm. Section 6 determines optimal degree of privatization. Section 7 concludes.

\section{Literature review}

The earlier works on privatization focuses on the choice between complete privatization and complete nationalization as an effective policy tool in a closed-economy framework. Harris and Wiens (1980), Beato and Mas-Colell (1984), Cremer et al. (1989) and Barros (1995) show how a public firm can be used to correct the inefficiencies created by the imperfectly competitive markets. Since the public firm acts as a disciplining device to obtain the first best allocation of outputs, the above mentioned papers are in favour of complete nationalization. ${ }^{5}$

Analyzing the implications of privatization under different market structures, Rees (1988) and De Fraja and Delbono (1989) show that privatization could also be welfare enhancing. Fershtman (1990) provides the rationale for privatization in the presence

domestic investors only (Kapur and Ramamurti, 2002). Countries often restrict foreign individuals and firms from acquiring domestic firms, or apply special restrictions to foreign firms in certain industries, as is the case in Malaysia and the Republic of Korea (UNCTAD, 2000). Of the 650 major privatization deals analyzed by Bortolotti et al. (2002) from the Privatization International dataset, only around HOW MANY involved an equity issue on non-domestic markets.

${ }^{5}$ See Vickers and Yarrow (1991), Schmidt and Schnitzer (1997) and Pal and White (1998) for overviews of the privatization literature. 
of cost asymmetry between the firms. Anderson et al. (1997) show that the presence of the public firm is a source of welfare loss since it deters entry of firms by keeping the price low. Hence, the beneficial effect of entry creates the rationale for privatization in their analysis.

Matsumura (1998) determines the optimal degree of privatization in a mixed duopoly and shows that, irrespective of the firms' cost structures, the public firm should be (at least partially) privatized except in the case where the private firm cannot enter the market. Bárcena-Ruiz and Casado-Izaga (2012) examine the location choice in a mixed duopoly when the costs are endogenously determined and find that the location decisions of the firms are made simultaneously when the objective function of the public firm has more weight on its profit and sequentially when not. Jain and Pal (2012) investigate the effects of cross-ownership on optimal privatization, and vice-versa, and show that cross-ownership is profitable to the private firm only if the level of privatization of the public firm is sufficiently high. However, the possibility of cross-ownership significantly limits the socially optimal level of privatization in most of the situations.

All the above-mentioned papers consider privatization in a closed economy. Although these studies have their own merits, they may not be appropriate for economies with a significant presence of foreign firms, as considered in our paper.

In a seminal paper, Corneo and Jeanne (1994) consider mixed oligopolies in the presence of foreign competition. They show that the countries with public firms will be net exporters. They also show how nationalization and privatization of firms affect world as well as national welfare.

Other papers that examine privatization and open economies mainly focuses on the strategic trade policy issues. While Pal and White (1998) investigate the effects of privatization in the presence of strategic trade policies such as domestic production subsidies and import tariffs, Fjell and Heywood (2002) show that the effects of privatization on firms' outputs, profits and welfare depend on the number of domestic and foreign firms. Matsumura et al. (2009) extend Anderson et al. (1997) with foreign competition and show that privatization increases (decreases) welfare in the long (short) run. Lin and Matsumura (2012) show how the presence of foreign investors 
in privatized firms affects privatization policy in a mixed oligopoly and find that an increase in the stockholding ratio of foreign investors in a privatized firm increases the optimal degree of privatization, whereas an increase in the penetration of foreign firms in product markets reduces it.

Mukherjee and Suetrong (2009) show that privatization of a public firm in the host country increases a foreign firm's incentive for FDI and the presence of FDI generally gives the government a higher incentive to privatize. However, as mentioned already, they ignore the tax/subsidy policies which help to reduce the distortion in the productmarket due to imperfect competition. We focus on this issue. Like Mukherjee and Suetrong (2009), we find that privatization generally increases the incentive for FDI. However, unlike them, the possibility of FDI in our analysis reduces the incentive for privatization.

\section{The model}

Consider a two-country model with country $f$, a (developed) foreign country and country $h$, a (developing or transition) domestic country. There is a firm in each country producing a homogeneous good and competing under Cournot competition. Firm $p$, located in the domestic country $h$, is a public (or state-owned) firm and firm $m$, located in the foreign country, is a private firm. These firms compete in the domestic country. Firm $m$ can serve the domestic country either through export or through FDI. Under export, firm $m$ needs to incur a per-unit transportation cost $s$. If firm $m$ undertakes FDI, it needs to invest a fixed amount $F .{ }^{6}$ We assume that the firms face production tax/subsidies imposed by the respective government conditional on export and FDI by firm $m$.

The inverse market demand function in the domestic country is:

$$
P=1-q_{m}^{\sigma}-q_{p}^{\sigma}
$$

where $P$ is price and $q_{i}^{\sigma}$ is the output of firm $i, i=p, m$, in scenario $\sigma=x, R$, where $x$ and $R$ denote export and FDI respectively.

\footnotetext{
${ }^{6} F$ captures all the start-up costs of a new plant, including the adjustment cost of learning to operate in a new institutional and financial environment.
} 
We assume that the constant marginal cost of firm $p$ is $c<1$. Firm $m$ is more cost efficient than firm $p$ and has a constant marginal of $w<c$. For simplicity, we normalize $w$ to 0 . We further assume that

$$
s<c,
$$

i.e. the foreign firm has a marginal cost advantage even under export.

We assume that the outputs of the firms are always positive, which implies that (see Appendix A):

$$
c<\hat{c} \equiv \hat{c}(1)=\frac{2}{5} .
$$

Let us now consider the objective functions of the firms. While firm $m$ maximizes profit, the objective function of the (semi) public firm $p$ depends on the firm's share distribution between the government and the private owners of the domestic country. Following the existing literature,(eg. Matsumura, 1998, Mukherjee and Suetrong, 2010), we assume that firm $p$ maximizes a convex combination of domestic profit and domestic welfare, where the weights on profits and welfare are given by the fractions of shareholdings by the domestic-country investors and the domestic government. We assume that firm $p$ is initially completely nationalized, which means that its objective is to maximize welfare of the domestic country.

A partially privatized firm $p$ maximizes the following expression

$$
o b j^{\sigma}=\alpha \Pi_{p}^{\sigma}+(1-\alpha) W_{h}^{\sigma},
$$

where $\Pi_{p}^{\sigma}$ and $W_{h}^{\sigma}$ are the profit of firm $p$ and welfare of the domestic country respectively in scenario $\sigma, \sigma=x, R$ and $\alpha$ is the degree of privatization. Note that complete nationalization $(\alpha=0)$ and complete privatization $(\alpha=1)$ are the special cases of (4). As $\alpha$ increases, it reduces the fraction of shareholding by the government and firm $p$ moves more towards profit maximization.

We consider the following game. In stage one, the domestic country determines the degree of privatization. In stage two, firm $m$ decides whether to export or to undertake FDI. In stage three, the governments set the product tax/subsidy rates that maximize their country's welfare. In stage four, the two firms set their output levels 
simultaneously ${ }^{7}$. We solve the game through backward induction.

\section{Tax policy}

We analyze the third and fourth stages of the game in this section. At stage three, the governments decide on the strategic tax/subsidy policies and the firms set their respective output levels at stage four. In subsection 4.1 (4.2), we analyze the subgame where the foreign firm has decided to export (undertake FDI).

\subsection{Export by the foreign firm}

In this subgame, the foreign firm has decided to export to the domestic country $h$. We start our analysis from stage four where the firms set their output levels simultaneously to maximize their respective objective functions.

From (1) and (4), the objective function of the domestic firm $p$ is:

$$
o b j_{p}^{x}=\alpha\left(1-q_{m}^{x}-q_{p}^{x}-t_{h}^{x}-c\right) q_{p}^{x}+(1-\alpha) W_{h}^{x}
$$

where the domestic country's welfare $W_{h}^{x}$ consists of firm $p$ 's profit, consumer surplus and tax revenue which is given by:

$$
W_{h}^{x}=\left(1-q_{m}^{x}-q_{p}^{x}-t_{h}^{x}-c\right) q_{p}^{x}+\frac{1}{2}\left(q_{p}^{x}+q_{m}^{x}\right)^{2}+t_{h}^{x} q_{p}^{x} .
$$

The objective of the foreign firm $m$ is to maximize its profits. From (1):

$$
\Pi_{m}^{x}=\left(1-q_{m}^{x}-q_{p}^{x}-t_{f}^{x}-s\right) q_{m}^{x}
$$

We find that the equilibrium outputs of firms $p$ and $m$ are, respectively:

$$
q_{p}^{x}=\frac{2-2 c-\alpha+s \alpha+\alpha t_{f}-2 \alpha t_{h}}{\alpha+2}, \quad q_{m}^{x}=\frac{c+\alpha+\alpha t_{h}-s-s \alpha-t_{f}-\alpha t_{f}}{\alpha+2}
$$

In stage three, the domestic and foreign governments set the respective welfaremaximizing tax rates subject to $q_{m}^{x}$ and $q_{p}^{x}$ given by (8). Maximizing domestic welfare $W_{h}^{x}$ in (6) with respect to $t_{h}^{x}$ and solving for $t_{h}^{x}$ we get:

$$
t_{h}^{x}=\frac{c-3 \alpha+2 c \alpha-\left(t_{f}+s\right)(-\alpha+1)}{3 \alpha} .
$$

\footnotetext{
${ }^{7}$ Our assumption implies that privatization is more irreversible than FDI, which is more irreversible than tax/subsidy policy and it is more irresible than output decision.
} 
The foreign country's welfare $W_{f}^{x}$ consists of firm $m$ 's profit and the tax revenue:

$$
W_{f}^{x}=\Pi_{m}^{x}+t_{f}^{x}\left(q_{m}^{x}\right),
$$

where $q_{m}^{x}$ and $q_{p}^{x}$ are given by (8) and $\prod_{m}^{x}$ given by (7). Maximizing with respect to $t_{f}^{x}$ yields:

$$
t_{f}^{x}=\frac{-\alpha\left(c-s+\alpha-s \alpha+\alpha t_{h}\right)}{2 \alpha+2} .
$$

Solving (9) and (11) for $t_{f}^{x}$ and $t_{h}^{x}$ yields: ${ }^{8}$

$$
\begin{aligned}
t_{f}^{x} & =-2 \alpha \frac{c-s}{\alpha+3}<0 \\
t_{h}^{x} & =\frac{-(1-s) \alpha^{2}-3(1-c) \alpha+(c-s)}{\alpha(\alpha+3)} .
\end{aligned}
$$

Differentiating with respect to $\alpha$, we see that:

$$
\begin{aligned}
& \frac{d t_{h}^{x}}{d \alpha}=-(c-s) \frac{2 \alpha+3 \alpha^{2}+3}{\alpha^{2}(\alpha+3)^{2}}<0 \\
& \frac{d t_{f}^{x}}{d \alpha}=-\frac{6}{(\alpha+3)^{2}}(c-s)<0 .
\end{aligned}
$$

From (13), we see that the home firm receives subsidy under complete privatization, and as the degree of privatization decreases, it reduces the subsidy and if the degree of privatization is small, the home firm faces a tax. The reason for this result is as follows. If there is complete privatization, the home government wants to sudsidize the profit maximizing domestic firm to reduce the output market distortion created by the imperfect competition in the product market. However, as the degree of privatization reduces, the home firm starts putting more emphasis on welfare maximization, thus reducing the need for subsidization to eliminate the inefficiency from imperfect competition. If the home firm is significantly nationalized, the motive for rent extraction from the foreign firm induces the domestic government to impose a tax on the domestic firm.

While the domestic firm may receive subsidy or face taxation, the foreign firm always receives subsidy and the subsidy rate increases with privatization. The rent

\footnotetext{
${ }^{8}$ The domestic country's product tax rate is indeterminate for $\alpha=0$. This is because a fully nationalized firm sees the tax as transferring funds from the firm to the government without affecting welfare, which is what the firm maximizes. From (5) and (6) with $\alpha=0, t$ drops out of the firm's objective function: The tax does not affect the firm's behavior.
} 
extraction motive of the foreign government induces it to subsidize the foreign firm, and this motive gets stronger as the degree of privatization increases, since a higher degree of privatization increases subsidization by the domestic government. ${ }^{9}$

Substituting (13) and (12) into (8), we find the equilibrium output of the domestic firm as:

$$
q_{p}^{x}=\frac{-2 c(\alpha+2)+(\alpha+1) s+(\alpha+3)}{\alpha+3}
$$

which is decreasing in $\alpha$ as:

$$
\frac{d q_{p}^{x}}{d \alpha}=-\frac{2}{(\alpha+3)^{2}}(c-s)<0 .
$$

Substituting (13) and (12) into (8), we find the equilibrium output of the foreign firm as:

$$
q_{m}^{x}=2(\alpha+1) \frac{c-s}{\alpha+3}>0
$$

which is increasing in $\alpha$ as:

$$
\frac{d q_{m}^{x}}{d \alpha}=\frac{4}{(\alpha+3)^{2}}(c-s)>0 .
$$

Privatization creates two opposing effects on the domestic firm's output. On one hand, it tends to reduce the domestic firm's output for a given tax/subsidy, since privatization reduces the emphasis on welfare maximization. On the other hand, a higher degree of privatization tends to increase its output by increasing the subsidy rate. We find that the first effect dominates the second effect and a higher degree of privatization reduces the domestic firm's output.

A higher degree of privatization increases the foreign firm's output for two reasons. First, a higher degree of privatization increases subsidization by the foreign government, which tends to increase the foreign firm's output. Second, a higher degree of privatization reduces the output of the domestic firm, thus increasing the residual demand for the foreign firm, which, in turn, helps to increase the foreign firm's output.

From (15) and (17), the total output is increasing in $\alpha$ :

$$
\frac{d\left(q_{p}^{x}+q_{m}^{x}\right)}{d \alpha}=\frac{2[c-s]}{(\alpha+3)^{2}}>0 .
$$

\footnotetext{
${ }^{9}$ The motive for subsidization to extract rent from the firms in competing countries dates back to seminal work by Brander and Spence (1985).
} 
The inequality follows from (2) and suggests that the effects of subsidies dominate the effect of a lower emphasis on welfare in the domestic firm, thus increasing the total output following privatization. Hence, price falls or consumer surplus increases with higher $\alpha$. This is in contrast to the general belief that the higher degree of privatization reduces consumer surplus by encouraging the public firm to move more towards profit maximization (e.g., see, Mukherjee and Suetrong, 2009). However, this reasoning ignores strategic tax/subsidy policies. We show that the presence of strategic tax/subsidy policies may change the effect of privatization on consumers.

Substituting (16), (14) and (12) into the profit function (7), we obtain the profit of the foreign firm under export as:

$$
\Pi_{m}^{x}=4(\alpha+1)^{2} \frac{(c-s)^{2}}{(\alpha+3)^{2}} .
$$

\subsection{FDI by the foreign firm}

In this sub-game, the foreign firm has decided, in stage one, to relocate its plant to the domestic country, i.e. undertaking FDI.

At stage four, each firm sets the output level that maximizes its objective function. The maximization problem for the domestic firm is:

$$
o b j^{R}=\alpha\left(1-q_{m}^{R}-q_{p}^{R}-t_{h}^{R}-c\right) q_{p}^{R}+(1-\alpha) W_{h}^{R} .
$$

The domestic country's welfare $W_{h}^{R}$ consists of firm $p$ 's profit, consumer surplus and tax revenue given by:

$$
W_{h}^{R}=\left(1-q_{m}^{R}-q_{p}^{R}-t_{h}^{R}-c\right) q_{p}^{R}+\frac{1}{2}\left(q_{p}^{R}+q_{m}^{R}\right)^{2}+t_{h}^{R}\left(q_{p}^{R}+q_{m}^{R}\right) .
$$

The objective of the foreign firm is to maximize its profits $\Pi_{m}^{R}$. From (1):

$$
\Pi_{m}^{R}=\left(1-q_{m}^{R}-q_{p}^{R}-t_{h}^{R}\right) q_{m}^{R}-F
$$

We find that the equilibrium outputs of the firms are respectively:

$$
q_{p}^{R}=\frac{2-2 c-\alpha-\alpha t_{h}}{\alpha+2}, \quad q_{m}^{R}=\frac{c+\alpha-t_{h}}{\alpha+2} .
$$


In stage three, the domestic government sets the tax rate that maximizes its welfare $W_{h}^{R}$ given by (20) with $q_{m}^{R}$ and $q_{p}^{R}$ given by (22). Maximizing (20) and solving for $t_{h}^{R}$ yields:

$$
t_{h}^{R}=\frac{\left(c+\alpha+c \alpha-\alpha^{2}+c \alpha^{2}\right)}{2 \alpha+\alpha^{2}+3}>0 .
$$

We further see that the tax rate under FDI is first increasing and then decreasing with privatization. This is because under full nationalization, the home government's strategic policy is dominated by the motive for rent extraction from the foreign firm. Hence, we see that when $\alpha=0, t_{h}^{R}=\frac{c}{3}$. However, as the degree of privatization increases, the domestic firm becomes more profit-oriented, thus reducing the emphasis on welfare, which encourages the government to decrease the tax rate for increasing consumer surplus.

Substituting (23) into (22), we find the respective equilibrium outputs of the domestic and the foreign firms as:

$$
\begin{aligned}
q_{p}^{R} & =\frac{3-3 c-\alpha-c \alpha-c \alpha^{2}}{2 \alpha+\alpha^{2}+3} \\
q_{m}^{R} & =\frac{c+\alpha+\alpha^{2}}{2 \alpha+\alpha^{2}+3} .
\end{aligned}
$$

We see that:

$$
\frac{d\left(q_{p}^{R}\right)}{d \alpha}=\frac{-6 \alpha-9+c\left(3-\alpha^{2}\right)+\alpha^{2}}{\left(\alpha^{2}+2 \alpha+3\right)^{2}} .
$$

The sign of the right hand side (RHS) of the above expression depends on the numerator which is positive for:

$$
c>\frac{1}{3-\alpha^{2}}\left(-\alpha^{2}+6 \alpha+9\right) \equiv c^{\prime} .
$$

We see that RHS of the above expression is increasing in $\alpha$. Setting $\alpha=1$ and considering the maximum value of $c$ from $(3)$, we see that $c^{\prime}$ is greater than our maximum possible value of $c$, i.e., $\hat{c}(1)=\frac{2}{5}$. Hence, RHS of (26) is negative implying that $q_{p}^{R}$ decreases with privatization. This result is due to the effects of privatization on the domestic firm's lower emphasis on welfare maximization and the effects of privatization on the tax rate. Lower emphasis on welfare under privatization helps to reduce domestic firm's equilibrium output. Privatization also increases the tax rate if the degree of privatization is not high, which, in turn, tends to reduce the domestic output. 
Although the tax rate falls when the degree of privatization is high, the significantly lower emphasis on welfare due to a large degree privatization dominates the effects of tax, and privatization reduces the equilibrium output of the domestic firm.

Similarly, differentiating $q_{m}^{R}$ with respect to $\alpha$, we obtain:

$$
\frac{d q_{m}^{R}}{d \alpha}=\frac{\left(\alpha^{2}+(6-2 c) \alpha+(3-2 c)\right)}{\left(\alpha^{2}+2 \alpha+3\right)^{2}}>0 .
$$

Hence, $q_{m}^{R}$ increases with privatization. With privatization, the domestic firm reduces its output, which, in turn, helps to increase the equilibrium output of the foreign firm. Although the foreign firm faces higher tax rate if the degree of privatization is not very high, the expansion of foreign firm's residual demand following the domestic firm's output contraction under privatization dominates the effects of a higher tax under privatization, and privatization increases the equilibrium output of the foreign firm.

Combining (26) and (27), it can be shown that the total output (and therefore, consumer surplus) is generally decreasing in $\alpha$, increasing only for very high values of $\alpha$. Higher tax rate and lower emphasis on welfare help to reduce the total output following privatization if the degree of privatization is not very high. However, a fall in the tax rate for a very degree of privatization helps to increase the total output following privatization even if privatization reduces the emphasis on welfare further.

Substituting (24), (25) and (23) into (21), the foreign firm's equilibrium profit under FDI is:

$$
\Pi_{m}^{R}=\left[\frac{\left(c+\alpha+\alpha^{2}\right)}{\left(2 \alpha+\alpha^{2}+3\right)}\right]^{2}-F
$$

\section{Export or FDI}

Having analyzed the third (government policy) and fourth (firms' output) stages of the game in the previous section, we now move to stage two where the foreign firm decides between export and FDI. The foreign firm prefers FDI (export) if $\Pi_{m}^{R}>(\leq) \Pi_{m}^{x}$.

Comparing the foreign firm's profits (19) under export and (28) FDI, we find that:

Lemma 1. The foreign firm prefers FDI to export if the fixed cost F of undertaking 
FDI is below $\hat{F}$, where

$$
\hat{F} \equiv\left[\frac{\left(c+\alpha+\alpha^{2}\right)}{\left(2 \alpha+\alpha^{2}+3\right)}\right]^{2}-\left[2(\alpha+1) \frac{(c-s)}{(\alpha+3)}\right]^{2}
$$

$\hat{F}$ shows the difference between the foreign firm's gross profit (i.e. profit including the relocation cost) under FDI and export, thus showing the foreign firm's maximum gross benefit from FDI compared to export. It is worth noting that $\hat{F}$ may be negative, implying FDI may not occur even if the fixed-cost of FDI is zero. $\hat{F}$ has to be positive for FDI to be profitable. It follows from Lemma 1 that:

Proposition 1. The foreign firm prefers FDI to export for low enough relocation cost $F$ if:

$$
\frac{\left(c+\alpha+\alpha^{2}\right)}{\left(2 \alpha+\alpha^{2}+3\right)}>2(\alpha+1) \frac{(c-s)}{(\alpha+3)}
$$

and this is satisfied if $c>c_{2}$, with $c_{2}$ given as:

$$
c_{2} \equiv(\alpha+1) \frac{6 s+3 \alpha+4 s \alpha+\alpha^{2}+2 s \alpha^{2}}{9 \alpha+6 \alpha^{2}+2 \alpha^{3}+3} .
$$

Calibrating with different feasible values of $c$ and $s$, we see that $\hat{F}$ is increasing monotonically in $\alpha \in[0,1]$. Further, we see that $\hat{F}(\alpha=0)$ could be negative, ${ }^{10}$ implying that the foreign firm could prefer not to undertake FDI under complete nationalization. However, privatization increases the foreign firm's incentive for undertaking FDI.

Since $\hat{F}(\alpha=0)<0$ and $\hat{F}$ is increasing monotonically in $\alpha \in[0,1]$, there can be a $\alpha$ in the interval $\alpha \in[0,1]$ where $F=\hat{F}$, i.e. firm $m$ is indifferent between FDI and export.

Let us denote by $\alpha_{F 1}$ the level of $\alpha$ where firm $m$ is indifferent between FDI and export. By Lemma 1, $\alpha_{F 1}$ is defined by:

$$
\left[\frac{\left(c+\alpha_{F 1}+\alpha_{F 1}^{2}\right)}{\left(2 \alpha_{F 1}+\alpha_{F 1}^{2}+3\right)}\right]^{2}+F=\left[2\left(\alpha_{F 1}+1\right) \frac{(c-s)}{\left(\alpha_{F 1}+3\right)}\right]^{2} \text {. }
$$

If $\alpha_{F 1}$ exists and $\alpha>\alpha_{F 1}$, firm $m$ prefers FDI to export.

\footnotetext{
${ }^{10}$ See Appendix $D$ for proof.
} 
Lemma 2: If there is no $\alpha_{F 1} \in[0,1)$ satisfying (32), firm $m$ exports for all $\alpha \in[0,1]$. If there is a $\alpha_{F 1} \in[0,1)$ satisfying (32), firm $m$ exports for $\alpha \in\left[0, \alpha_{F 1}\right]$ and undertakes FDI for $\alpha \in\left(a_{F 1}, 1\right]$.

As the fixed-cost of undertaking FDI increases, $\alpha_{F 1}$ increases within the range of $\alpha \in[0,1]$.

\section{Welfare analysis}

In this section, we first analyze the effect of privatization on domestic welfare under export and FDI by the foreign firm. Then we determine the domestic government's optimal degree of privatization conditional on the foreign firm's location decision.

\subsection{Under Export}

If the foreign firm exports, domestic welfare is given by (6), where $q_{p}^{x}$ is given by (14), $q_{m}^{x}$ is given by (16) and $t_{h}^{x}$ is given by (13). Substituting the respective values yields:

$$
W_{h}^{x}=\frac{1}{2} \frac{\left(4\left(3 \alpha+\alpha^{2}+3\right) c^{2}-3 s(\alpha+1)^{2}(2 c-s)-(\alpha+3)^{2}(2 c-1)\right)}{(\alpha+3)^{2}}
$$

and differentiating it with respect to $\alpha$, we see that welfare is increasing in $\alpha$ :

$$
\frac{d W_{h}^{\prime x}}{d \alpha}=6 \frac{\alpha+1}{(\alpha+3)^{3}}(c-s)^{2}>0 .
$$

Hence, the following result is immediate.

Proposition 2: If the foreign firm exports, complete privatization (i.e. $\alpha_{x}^{*}=1$ ) is the optimal policy of the domestic government.

The intuition is as follows. In the absence of strategic trade policy, privatization creates two effects. On one hand, it tends to increase the profit of the domestic firm. On the other hand, it tends to decrease consumer surplus. These two effects are similar to the effects shown in Mukherjee and Suetrong (2009), and make partial privatization the optimal domestic policy. However, as shown above, in contrast to the abovementioned second effect, privatization increases consumer surplus under endogenous 
strategic tax/subsidy policy, thus making complete privatization the optimal domestic policy under export by the foreign firm.

\subsection{Under FDI}

If the foreign firm undertakes FDI, domestic welfare is given by (20), where $q_{p}^{R}$ is shown in (24), $q_{m}^{R}$ is shown in (25) and $t_{h}^{R}$ is shown in (23). Domestic welfare under FDI is:

$$
W_{h}^{R}=\frac{1}{2} \frac{-6 c+2 \alpha+c^{2} \alpha^{2}-2 c \alpha-\alpha^{2}+2 c^{2} \alpha+4 c^{2}+3}{2 \alpha+\alpha^{2}+3} .
$$

Differentiating the above expression with respect to $\alpha$, we see that:

$$
\frac{d W_{h}^{R}}{d \alpha}=\frac{(c-2 \alpha+c \alpha)(\alpha-c+3)}{\left(\alpha^{2}+2 \alpha+3\right)^{2}},
$$

which gives the following result (see Appendix $B$ for the proof):

Proposition 3: If the foreign firm undertakes FDI, the optimal degree of privatization is partial and is equal to:

$$
\alpha_{R}^{*}=\frac{c}{2-c}<1
$$

In contrast to export by the foreign firm, we have seen that privatization decreases the total output under FDI except for very high degree of privatization. Hence, in our analysis, privatization under FDI generally creates a trade off between higher domestic profit and lower consumer surplus. This trade off, which is in contrast to the case under export but similar to the trade off shown in Mukherjee and Suetrong (2009), is responsible for creating partial privatization in our analysis under FDI.

The comparison of the degrees of privatization maximizing domestic welfare under export and FDI by the foreign firm follows immediately from Propositions 2 and 3:

$$
\alpha_{R}^{*}<\alpha_{x}^{*}=1
$$

It can also be shown that: ${ }^{11}$

$$
W_{h|\alpha=1|}^{x}>W_{h|\alpha=1|}^{R} \text { and } W_{h|\alpha=0|}^{R}>W_{h|\alpha=0|}^{x} .
$$

Lemma 3 If the domestic country privatizes completely, domestic welfare is higher under export than under FDI. Under complete nationalization, domestic welfare is higher under FDI than under export.

\footnotetext{
${ }^{11}$ See Appendices B and C for the proof.
} 


\subsection{Equilibrium degree of privatization}

Now we will determine the optimal degree of privatization conditional on the foreign firm's equilibrium decision on export or FDI. We will consider the following two cases separately:

(i) When the fixed-cost of undertaking FDI is so high that the foreign firm exports for all values of $\alpha$.

(ii) When the fixed-cost of undertaking FDI is intermediate such that $\alpha_{R}^{*}<\alpha_{F 1}<$ $1 .{ }^{12}$

The optimal degree of privatization for case (i) is immediate from Proposition 1, showing that complete privatization is the optimal choice of the domestic country. Hence, we concentrate on case (ii) in the following analysis.

In case (ii), privatization can induce the foreign firm to switch from export to FDI $\left(\alpha_{F 1}<1\right.$ in (32)). However, since welfare under FDI is decreasing in $\alpha$ for $\alpha>\alpha_{R}^{*}$, it is not immediate whether the domestic government will prefer to privatize to attract FDI. We have to see whether welfare at $\alpha_{F 1}$ is higher (as illustrated in Figure 1) or lower (as illustrated in Figure 2) under FDI compared to export.

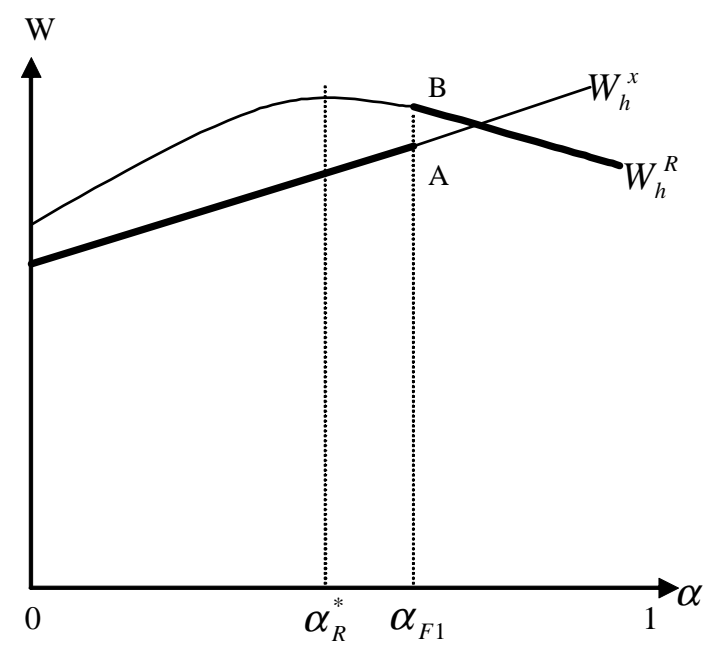

Figure 1: Figure 1: FDI under optimal privatization policy

Figure 1 considers the case where welfare at $\alpha_{F 1}$ is higher under FDI than under

\footnotetext{
${ }^{12}$ We show in Appendix E that $\alpha_{R}^{*}<\alpha_{F 1}$.
} 
export. In this case, firm $m$ exports until $\alpha_{F 1}$ and domestic welfare at $\alpha_{F 1}$ under export by the foreign firm is given by point $\mathrm{A}$ on $W_{h}^{x}$. If the degree of privatization is more than $\alpha_{F 1}$, firm $m$ undertakes FDI and domestic welfare follows the curve $W_{h}^{R}$ for $\alpha>\alpha_{F 1}$. Since domestic welfare is higher under FDI than under export at $\alpha_{F 1}$, the degree of privatization that maximizes domestic welfare conditional on FDI by firm $m$ is given by $\alpha_{F 1}+\varepsilon$, where $\varepsilon \rightarrow 0$, which is just sufficient to induce the foreign firm to undertake FDI. Hence, due to the firm $m$ 's strategic plant location decision, $\alpha_{F 1}+\varepsilon$ is the optimal degree of privatization and neither $\alpha_{R}^{*}$, since firm $m$ does not undertake FDI at $\alpha_{R}^{*}$, nor $\alpha_{x}^{*}=1$, since firm $m$ does not export at $\alpha_{x}^{*}=1$.

Now consider the situation where $\alpha_{F 1}>\alpha_{R}^{*}$ and domestic welfare at $\alpha_{F 1}$ is higher under export than under FDI by firm $m$, as shown in Figure 2. Similar to the previous case, the domestic country would try to attain the highest possible welfare conditional on firm $m$ 's plant location decision. Since firm $m$ undertakes FDI for $\alpha>\alpha_{F 1}$, the domestic government privatizes up to $\alpha_{F 1}$, which deters FDI and induces firm $m$ to export. Note that domestic welfare is maximized at $\alpha=1$ if firm $m$ exports at $\alpha=$ 1. However, since $\alpha=1$ induces firm $m$ to undertake FDI, the optimal degree of privatization is $\alpha_{F 1}$. Therefore, the threat of FDI encourages the domestic government to privatize partially, although FDI does not occur in equilibrium.

Figure 2 shows that privatization along with the FDI policies to reduce the fixedcost of undertaking FDI is required to attract FDI and to improve domestic welfare. If the FDI policy of the domestic country helps to reduce the fixed-cost of undertaking FDI, thus reducing $\alpha_{F 1}$, it may create a situation like Figure 1, where FDI occurs and domestic welfare is higher compared to the situation in Figure 2.

The following result is immediate from Propositions 2 and 3 and the above discussion.

Proposition 4: If the cost of undertaking FDI is such that the foreign firm exports up to $\alpha_{F 1}<1$, the optimal degree of privatization is either $\alpha_{F 1}+\varepsilon$ (if domestic welfare at $\alpha_{F 1}$ is higher under FDI than under export) or $\alpha_{F 1}$ (if domestic welfare at $\alpha_{F 1}$ is lower under FDI than under export). Hence, the credible threat of FDI by the foreign firm reduces the degree of privatization. 


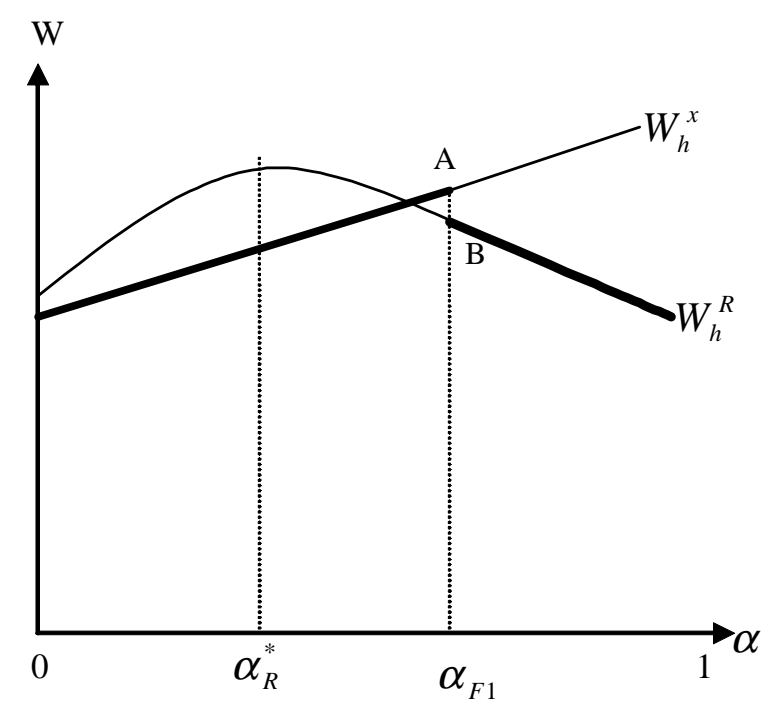

Figure 2: Export under optimal privatization policy.

The reason for the above result is easy to understand. For a given degree of privatization, on one hand, more cost efficiency under FDI (compared to export) due to the transport cost saving tends to increase domestic welfare, but on the other hand, FDI tends to reduce domestic welfare by reducing domestic profit. If the threat of FDI is credible, meaning that the foreign firm undertakes FDI for a degree of privatization that is less than 1, the negative effect of FDI on domestic profit reduces the domestic government's incentive for privatization compared to the situation where FDI does not occur for any degree of privatization. However, whether the domestic government wants FDI depends on the strengths of the negative effect of FDI on domestic profit and the positive cost efficiency effect. If the former effect is stronger, the domestic government wants to privatize in a way that maximizes domestic welfare conditional on no FDI by the foreign firm. If the domestic firm's profit loss is less important, the domestic government wants to attract FDI through privatization, yet the degree of privatization must be less than the degree of privatization when FDI is not an option, since FDI reduces the domestic welfare by shifting profit from the domestic firm to the foreign firm. 


\section{Conclusion}

We show the interaction between privatization and FDI in the context of strategic tax/subsidy policies. Privatization by the domestic country increases a foreign firm's incentive for FDI. However, the threat of FDI reduces the optimal degree of privatization compared to the situation with no FDI. Although complete privatization is optimal when FDI is not an option, partial privatization is optimal if FDI is a credible option. Whether the domestic government prefers FDI in equilibrium depends on the trade-off created by the negative effect of the domestic firm's profit loss and the positive effect of cost efficiency. If the domestic profit loss is significant, the domestic country prefers no FDI in equilibrium. In this situation, the privatization policy is designed to prevent FDI. However, if the loss in profit for the domestic firm is not significant, the domestic government privatizes up to the point that is just enough to induce FDI. Thus, we show that although privatization increases the incentive for FDI, the credible threat of FDI decreases the incentive for privatization, which is in contrast to the literature on privatization and FDI in the absence of strategic tax/subsidy policies (Mukherjee and Suetrong, 2009). Whether or not FDI occurs in equilibrium, we find that partial privatization is the equilibrium strategy.

There are, however, some important remarks to be made. We have abstracted in our analysis from other important factors that are relevant in the current world trade scenario. We have considered a non-polluting industry. However, the relationship between state ownership and FDI in the presence of environmental pollution is often considered to be important as FDI is often considered to be a source of environmental degradation in the host countries. ${ }^{13}$ However, similar results can be obtained when the model is extended to include environmental pollution as a by-product of production. ${ }^{14}$ In this case as well, privatization by the domestic country increases a foreign firm's incentive for FDI and the threat of FDI reduces the optimal degree of privatization compared to the situation of no FDI. The damage from pollution creates a further effect on privatization. If the damage from pollution is significant, the domestic country

\footnotetext{
${ }^{13}$ See Kellenberg (2009) for a survey of the literaure on environmental regulation and FDI.

${ }^{14}$ Details are available from the corresponding author upon request.
} 
prefers no FDI in equilibrium. In this situation, the privatization policy is designed to prevent FDI. However, if the damage from pollution is not significant, the domestic government privatizes up to the point that is just enough to induce FDI.

We have also assumed in our analysis that there is either no demand for the product in the foreign country or the foreign firm is always a monopolist in the foreign market. ${ }^{15}$ Hence, any change in the domestic country does not affect the outcome in the foreign country. A significant extension of this model would be to investigate the robustness of the model when introducing market demand in the foreign country. However, if there is demand in both the markets and the domestic firm $p$ can export to the foreign market, the subsidies would be further higher due to the rent extraction motive of the governments. In this case, the optimal degree of privatization would increase. However, if firm $p$ could relocate to the foreign country, either to serve the foreign market only or to serve both the markets through re-exporting, the strategic FDI and privatization decisions would be different. We leave this issue for future research.

\footnotetext{
${ }^{15}$ High cost needed to serve the foreign market may prevent the domestic firm from entering the foreign market. Das et al. (2007) show that there is a significant fixed cost of exporting. Moreover, buyer-seller networks may be important for both international trade and investment (Greaney, 2003), and high network costs may prevent the foreign firm in the model from serving the export markets.
} 


\section{Appendix}

\section{Appendix A: Maximum value of $c$ :}

We see from (14) and (24) that $q_{p}^{x}$ and $q_{p}^{R}$ are positive respectively for:

$$
\begin{aligned}
c & <\bar{c}(\alpha, s) \equiv \frac{1}{2 \alpha+4}(s+\alpha+s \alpha+3) \\
c & <\hat{c}(\alpha) \equiv \frac{3-\alpha}{\alpha+\alpha^{2}+3}
\end{aligned}
$$

We further see that:

$$
\frac{\partial \bar{c}(\alpha, s)}{\partial \alpha}<0 \text { and } \frac{d \hat{c}(\alpha)}{d \alpha}<0
$$

Following (A.3), the least possible values of (A.1) and (A.2) are respectively:

$$
\begin{aligned}
& c<\bar{c}_{\min } \equiv \bar{c}(1, s)=\frac{s+2}{3} \\
& c<\hat{c}_{\min } \equiv \hat{c}(1)=\frac{2}{5} .
\end{aligned}
$$

Comparing (A.4) and (A.5), we see that $\hat{c}(1)<\bar{c}(1, s)$. Hence, the relevant constraint is (3).

\section{Appendix B: $W_{h}^{R}$ as a function of $\alpha$ :}

Differentiating domestic welfare $W_{h}^{R}$ under FDI in (35) partially with respect to $\alpha$, we see that there are two solutions to $\partial W_{h}^{R} / \partial \alpha=0$, which we call $\underline{\alpha}$ and $\alpha_{R}^{*}$ :

$$
\underline{\alpha}=c-3, \quad \alpha_{R}^{*}=\frac{c}{2-c} .
$$

We see that $0<\alpha_{R}^{*}<1$ and $\underline{\alpha}$ is negative.

In order to determine whether these two stationary points are maxima or minima, we differentiate partially with respect to $\alpha$ again:

$$
\begin{aligned}
\left.\frac{d^{2}\left(W_{h}^{R}\right)}{d \alpha^{2}}\right|_{\alpha=\underline{\alpha}} & =\frac{1}{-4 c+c^{2}+6}>0, \\
\left.\frac{d^{2}\left(W_{h}^{R}\right)}{d \alpha^{2}}\right|_{\alpha=\alpha_{R}^{*}} & =-\frac{1}{4} \frac{(c-2)^{4}}{c^{2}-4 c+6}<0 .
\end{aligned}
$$

Hence, domestic welfare reaches a global maximum for $\alpha \in[0,1]$ at $\alpha=\alpha_{R}^{*}$ as given by (A.6). 


\section{Appendix C: $W_{h}^{R}$ is not higher than $W_{h}^{x}$ for $\alpha=1$ :}

Setting $\alpha=1$ in (35) we get the domestic welfare under FDI at $\alpha=1$ as:

$$
W_{h|\alpha=1|}^{R}=\frac{7 c^{2}-8 c+4}{12} .
$$

Similarly setting $\alpha=1$ in (33), we get domestic welfare under export at $\alpha=1$ as:

$$
W_{h_{|\alpha=1|}}^{x \max }=\frac{\left(7 c^{2}-8 c+4\right)-s(3)(2 c-s)}{8} .
$$

From (A.7) and (A.8), we see that:

$$
\frac{d\left(W_{h}^{x}-W_{h}^{R}\right)_{|\alpha=1|}}{d c}=-\frac{1}{12}(7 c+9 s-4)<0 .
$$

The minimum value of $\left(W_{h}^{x}-W_{h}^{R}\right)_{|\alpha=1|}$ is at the maximum value that $c$ can take. From (A.7), (A.8) and the maximum value of $c$ given by (3), we see that:

$$
\left(W_{h}^{x}-W_{h}^{R}\right)_{|\alpha=1|_{c_{\max }}}=\frac{1}{200}\left(-60 s+75 s^{2}+16\right)>0 .
$$

Thus, we see that

$$
W_{h|\alpha=1|}^{x}>W_{h|\alpha=1|}^{R}
$$

at $\alpha=1$. Also, setting $\alpha=0$,in (33) and (35) we see that:

$$
\left[W_{h}^{R}-W_{h}^{x}\right]_{\alpha=0}=\frac{1}{6} s(2 c-s)>0 .
$$

Appendix D: $\hat{F}$ could be negative at $\alpha=0$ :

Substituting $\alpha=0$ into (31), we see that $\hat{F}>0$ at $\alpha=0$ for:

$$
c>\check{c} \equiv 2 s .
$$

Thus, we see that when $c<\check{c}, \hat{F}$ is negative at $\alpha=0$.

Appendix E: $\alpha_{R}^{*}<a_{F 1}$ :

If $\alpha_{R}^{*}>a_{F 1}$, it implies from (29) that $\hat{F}$ should be positive at $\alpha=\alpha_{R}^{*} \equiv \frac{c}{2-c}$.

We see from $(29)$ that $\hat{F}_{\alpha=\alpha_{R}^{*}}>0$ for:

$$
c>\stackrel{\circ}{c} \equiv \frac{1}{2} \sqrt{16 s+1}-\frac{1}{2} .
$$

However, for this to be consistent with the model setting, $\stackrel{\circ}{c}$ should be less than $\hat{c}$ in (3). On comparison from (A.11) and (3), we see that $\stackrel{\circ}{c}<\hat{c}$ for $s<0.14$. Thus, for cases where $s<0.14$, we see that $\alpha_{R}^{*}>a_{F 1}$. 


\section{References}

[1] Anderson, S.P., A.d. Palma and J-F. Thisse (1997), 'Privatization and efficiency in a differentiated industry', European Economic Review, 41: 1635-54.

[2] Baer, W. (1994), 'Privatization in Latin America', The World Economy, 17: 50928.

[3] Brander, J. and B. Spencer (1985), 'Export subsidies and international market share rivalry', Journal of International Economics, 18: 83-100.

[4] Bárcena-Ruiz , J. and F. Casado-Izaga, 2012. "Location of public and private firms under endogenous timing of choices," Journal of Economics, 105: 129-143.

[5] Barros, F (1995), 'Incentive schemes as strategic variables: an application to a mixed duopoly', International Journal of Industrial Organization, 13: 373-86.

[6] Beato, P. and A. Mas-Colell (1984), 'The marginal cost pricing rule as a regulation mechanism in mixed markets', in: Marchand, M., P. Pestieau and H. Tulkens (eds.), The performance of public enterprises, North-Holland, Amsterdam.

[7] Bortolotti, B., M. Fantini and C. Scarpa ( 2002), 'Why do governments privatize abroad?', International Review of Finance, 3: 121-63.

[8] Corneo, G. and Jeanne, O. (1994), 'Oligopole mixte dans un marché commun', Annales d'Economie et de Statistique, ENSAE, 33: 73-90.

[9] Cremer, H., M. Marchand and J-F. Thisse (1989), 'The public firm as an instrument for regulating an oligopolistic market', Oxford Economic Papers, 41: 283-301.

[10] Das, S., M.J. Roberts and J.R. Tybout (2007), 'Market entry costs, producer heterogeneity and export dynamics', Econometrica, 75: 837-73.

[11] De Fraja, G. and F. Delbono (1989), 'Alternative strategies of a public enterprise in oligopoly', Oxford Economic Papers, 41: 302-11. 
[12] Fershtman, C. (1990), 'The interdependence between ownership status and market structure: The case of privatization', Economica, 57: 319-28.

[13] Fjell, K. and J. S. Heywood (2002), 'Public Stackelberg leadership in a mixed oligopoly with foreign firms', Australian Economic Papers, 41: 267-81.

[14] Gani, A. (2005), 'Foreign direct investment and privatization', USPEC Working Paper, No. 2005/6, Department of Economics, University of The South Pacific.

[15] Greaney, T.M. (2003), 'Reverse importing and asymmetric trade and FDI: a networks explanation', Journal of International Economics, 61: 453-465.

[16] Harris, R.G., and E.G. Wiens (1980), 'Government enterprise: an instrument for the internal regulation of industry', Canadian Journal of Economics, 13: 125-32.

[17] Jain, R. and Pal, R. (2012), 'Mixed duopoly, cross-ownership and partial privatization,' Journal of Economics, 107: 45-70.

[18] Kapur, D. and R. Ramamurti (2002), 'Privatization in India: the imperatives and consequences of gradualism', in: Srinivasan, T.N. (ed.), India After a Decade of Economic Reforms: Retrospect and Prospects, Stanford University Press.

[19] Kellenberg, D.K. (2009), 'An empirical investigation of the pollution haven effect with strategic environment and trade policy', Journal of International Economics, 78: $242-255$.

[20] Merlevede, B. and K. Schoors, (2005), 'How to catch foreign fish? FDI and accession countries', Working Paper, No. 785, William Davidson Institute.

[21] Matsumura, T. (1998), 'Partial privatization in mixed duopoly', Journal of Public Economics, 70: 473-83.

[22] Matsumura, T. and O. Kanda (2005), 'Mixed oligopoly at free entry markets', Journal of Economics, 84: 27-48. 
[23] Matsumura, T., N. Matsushima, N. and I. Ishibashi (2009), 'Privatization and entries of foreign enterprises in a differentiated industry', Journal of Economics, 98: 203-219.

[24] Matsumura, T. and Lin, M.H (2012), 'Presence of Foreign Investors in Privatized Firms and Privatization Policy', Journal of Economics, 107: 71-80.

[25] Mukherjee, A. and K. Suetrong (2009), 'Privatization, strategic foreign direct investment and host-country welfare', European Economic Review, 53: 775-785.

[26] Pal, D. and M.D. White (1998), 'Mixed oligopoly, privatization, and strategic trade policy', Southern Economic Journal, 65: 264-81.

[27] Rees, R. (1998), 'Inefficiency, Public Enterprise and Privatisation', European Economic Review, 32: 422-431.

[28] Schmidt, K.M. and M. Schnitzer (1997), 'Methods of privatization: auctions, bargaining and give-aways', CEPR Discussion Paper, No. 1541.

[29] UNCTAD (2000), World Investment Report, United Nations, New York and Geneva.

[30] UNCTAD (2002), World Investment Report, United Nations, New York and Geneva.

[31] Vickers, J. and G. Yarrow, (1991), 'Economic perspectives on privatization', Journal of Economic Perspectives, 5: 111-32. 